Running head: PURPOSE-DRIVEN LIFE

Purpose-Driven Life:

Life Goals as a Predictor of Quality of Life and Psychological Health

Esther Yuet Ying LAU ${ }^{\mathrm{a}}$, Sing-Hang CHEUNG ${ }^{\mathrm{a}}, \mathrm{Jasmine} \mathrm{LAM}^{\mathrm{a}}$, C. Harry HUI ${ }^{\mathrm{a}}$, Shu-Fai CHEUNG ${ }^{\mathrm{b}}$, and Doris Shui Ying MOK ${ }^{\mathrm{b}}$

${ }^{a}$ Department of Psychology, University of Hong Kong, Centennial Campus, Pokfulam Road, Hong Kong.

${ }^{\mathrm{b}}$ Department of Psychology, University of Macau, Avenue Padre Tomas Pereira, Taipa, Macau

Correspondence should be sent to Esther Y. Y. Lau, Department of Psychology, University of Hong Kong, Centennial Campus, Pokfulam Road, Hong Kong. E-mail: eyylau@hku.hk. We are grateful to Clark Campbell, Max Hui-Bon-Hoa, the two anonymous reviewers, and the editor for helpful suggestions on an earlier version of the manuscript. 
PURPOSE-DRIVEN LIFE

\begin{abstract}
On the basis of self-determination theory, we predicted that the pursuit of material goals might negatively affect quality of life and psychological outcomes including sleep quality and mood states. We further hypothesized that the link between religious affiliation and these outcome variables could be explained, at least partially, by life goals. Longitudinal data collected from 700 Chinese adults demonstrated that for both Christians and non-believers, material goals had a detrimental effect on outcome variables measured six months later. More importantly, material goals partially mediated the effects of religious affiliation. That is, Christians were different from non-believers on the outcome variables partly because the former did not go after material goals. For these believers, moreover, the pursuit of religion-based goals brought psychological benefits. Not only can certain life goals explain why people with religious faiths have better psychological health and quality of life, they can also explain why not every religious person feels good and is content about their lives.
\end{abstract}

Keywords: life goals; quality of life; sleep quality; mood; religiosity 
PURPOSE-DRIVEN LIFE

\section{Purpose-Driven Life:}

\section{Life Goals as a Predictor of Quality of Life and Psychological Health}

Life goals are the personally meaningful pursuits that we construe for ourselves and try to attain in our everyday activity (Brunstein 1993). They direct future life, guiding the person in making everyday choices. In this study, we examined the effect of two life goals on people's quality of life, moods, and sleep quality, as well as determined if life goals could be an explanation for the link between religious affiliation and these outcomes.

\section{Life Goals and Psychological Health Outcomes}

Relationships between pursuing and attaining life goals and psychological outcomes have been reported for both patient and community samples. Among university students, positive affect was found to be related to the value and past fulfillment of personal strivings, while negative affect was related to low probability of striving for success in the future, betweenstriving conflicts, and ambivalence (Emmons 1986). King (2001) found that undergraduates randomly assigned to write about their life goals 20 minutes per day for four days in a week reported improved well-being, and felt less upset than those assigned to write about their most traumatic life event. Similar results were recently obtained by Teismann et al. (2013). Conrad and colleagues (2010) reported successful goal attainment as an important predictor of wellbeing in rehabilitating patients with acquired brain injury. This and 84 other studies were included in a recent meta-analysis involving 20,653 individuals. There was a medium-to-large correlation (rho $=.43$ ) between successful goal pursuit and subjective well-being (Klug and Maier 2014). McNamara, Durso and Harris (2006) found a correlation between the subjective importance ratings of certain life goals and mood functioning among patients with Parkinson's disease. Goal derailment was also found to be associated with mood and cognitive impairment. 
PURPOSE-DRIVEN LIFE

Using an adolescent sample, Gabrielsen, Ulleberg, and Watten (2012) found happiness, life satisfaction, and self-efficacy to be related to the perceived importance and attainability of several life goals, whether they concern achievements or relations.

In contrast, the goal contents theory (which is a mini-theory of the self-determination theory, SDT, Deci and Ryan 2000; Kasser and Ryan 1996; Vansteenkiste et al. 2006) posits that goal content is just as important as goal attainment. It distinguishes between goals that are intrinsic (i.e., building closer relationships, achieving autonomy, making community contribution, etc.) and goals that are extrinsic (i.e., building transient resources such as money, fame or appearance). It further argues that people who regard intrinsic goals as more central to their lives experience greater psychological well-being, less depression, and fewer physical symptoms than do those who regard extrinsic goals as central (Vansteenkiste et al. 2008).

Indeed, there is empirical evidence in support of the goal contents theory. For example, Emmons (2003) showed that well-being was higher among people who had high intimacy strivings (i.e., concern for deep, gratifying interpersonal relationships built upon trust and affection). Similar association was found for generativity strivings (i.e., giving of oneself to others, and concern for future generations). People with high power strivings (i.e., to impress, control, and influence others) have lower well-being. While students who focused on achievement goals (e.g., to study a new language, etc.) had high self-esteem, so were those who did not pursue self-related goals such as to grow as a person and to play golf, etc. (Salmela-Aro and Nurmi 1997). Moreover, those who focused on family goals (e.g., to find a spouse) showed a decrease in depression and an increase in self-esteem over the subsequent two years. Furthermore, people who thought more about their own intrinsic values tended to experience better well-being (Lekes et al. 2012), while those who had a materialistic inclination had lower 
PURPOSE-DRIVEN LIFE

life satisfaction (Keng et al. 2000; Norris and Larsen 2011). In addition, intrinsic goals were associated with healthy lifestyles such as abstinence from tobacco (Niemiec et al. 2009), while extrinsic goals are associated with multiple health risk behaviors such as use of tobacco, alcohol, and marijuana, as well as sexual intercourse (Williams et al. 2000).

According to the SDT and the goal contents theory, the contents of intrinsic goals, in contrast to the extrinsic ones, would predict psychological well-being because they align with basic human psychological needs such as autonomy, competence, and relatedness (e.g., Emmons 2005; Kasser and Ryan 1996). In contrast, extrinsic work values, relative to intrinsic values, are associated with poorer work outcomes (Vansteenkiste et al. 2007). These effects were mediated by the lack of satisfaction of the basic psychological needs. In fact, materialism has been linked to poor well-being (e.g., Christopher et al. 2009; Roberts and Clement 2007). Headey (2008) found that pursuit of success goals (e.g., being able to buy things, fulfilling one's potentials, and success in job) over a ten-year period negatively predicted life satisfaction among Germans. In short, centrality of intrinsic goals was related to well-being and adjustment (Kasser and Ahuvia 2002; Kasser and Ryan 1996; Sheldon et al. 2004). In the present study we sought a conceptual replication of this relationship with a Chinese sample:

H1: The pursuit of material goals would negatively predict quality of life and sleep quality, while positively predicting depressive moods, anxiety, and stress at a later time.

\section{Religion-based Life Goals and Psychological Health Outcomes}

Some life goals are based on certain religious teachings, while others are explicitly discouraged within certain religious communities. Examples of the former in the Christian religion include theistic goals such as to "discern and follow God's will for my life", "have a closer relationship with God" (Leak et al. 2007), to "be active in religious life" (Richards 1966), 


\section{PURPOSE-DRIVEN LIFE}

and so forth. On the contrary, material goals are often regarded as unimportant or even evil from the biblical perspective. As Jesus warned, "Watch out, and be on your guard against all kinds of greed, life does not consist in the abundance of possessions" (Luke 12:15, NIV).

Although it is debatable whether the Christian religion has prescribed a set of life goals for its believers to pursue, a perusal of some Christian classics (e.g., Calvin 1536/1995) reveals certain consistent themes. These include: to develop a deeper communion with God, to know God and His work better, to volunteer and serve others, and to tell others about the faith. Although the pursuit of these life goals are sometimes associated with the promise of an abundant life, as in the text "it is more blessed to give than to receive" (Acts 20:35), more often the goals are presented as intrinsic in nature.

Like other intrinsic life goals, those with religious overtones have been found to relate to positive psychological outcomes. Emmons (2003) discussed findings that well-being was associated with spiritual strivings (i.e., commitment to the divine, and concern for ultimate and sacred purposes). Among individuals with neuromuscular disease, Emmons (2005) found that religious goals accounted for $39 \%$ to $44 \%$ of the variance in ratings of subjective well-being. Because believers who hold these goals put their attention on things that are "other-worldly", they have less concern for and less worry about "earthly" things, potentially leading to better moods. Leak et al. (2007) reported that vitality (comprising purposefulness and a sense of aliveness) and satisfaction with life were correlated with theistic goals and spiritual goals, but not with self-oriented goals in undergraduates.

Findings from previous studies using cross-sectional design suggest a causality which we tested and extended in the following hypothesis: 
PURPOSE-DRIVEN LIFE

$\mathrm{H} 2$ : Christian goals would positively predict quality of life and sleep quality, while negatively predicting depressive moods, anxiety, and stress among Christian believers at a later time.

\section{Religious Affiliation and Psychological Health Outcomes}

A related body of literature has shown a robust link between religious affiliation and positive outcomes. Religious people had better health and lower mortality risk (Chida et al. 2009; McCullough et al. 2000; Nicholson et al. 2009; Plante and Sherman 2001). They adjusted better to stress (Ano and Vasconcelles 2005) and showed fewer depressive symptoms (Bennett and Shepherd 2013; Smith et al. 2003). People who self-identified as religious were better in physical and psychological health, even after controlling for job satisfaction, marital satisfaction, and financial status (Green and Elliott 2010). Longitudinal data showed that Christian conversion in a summer camp improved moral sociability functioning as well as intrapsychic functioning (Schnitker et al. 2014). The latter included satisfaction with life, self-esteem, vitality, low depression, and low loneliness. Using a panel dataset, Headey et al. (2010) demonstrated that increase in frequency of religious activities over a ten-year period predicted improvement in life satisfaction during the same period.

Explanations offered for this relationship included the availability of social support network to religious people (Ellison 1991), opportunities for social involvement or participation (Koenig et al. 1998; Shor and Roelfs 2013), the believers' perceived control (Jackson and Bergeman 2011), and use of religious coping (Koenig et al. 1995). In a questionnaire study, Lawler-Row (2010) found trait forgiveness fully mediated the link of religiosity to illness symptoms. Some cross-sectional data suggested that the increase of self-esteem and self-efficacy 
PURPOSE-DRIVEN LIFE

as a result of religious participation could be an explanation for well-being (Ellison 1993; Krause 1995).

There can be an additional/alternative explanation, in terms of the influence religiosity has on the selection of goals. As Saroglou, Delpierre, and Dernelle's (2004) meta-analysis found, religious people eschewed values such as pursuing pleasure and having excitement in life. Moreover, religious teachings increased the importance of certain goals by sanctifying them (McCullough and Willoughby 2009). As a result, the believer's attention is focused not on extrinsic goals but rather on the religion-based goals described in the previous subsection. Pursuit of those goals may bring about behaviors that will result in contentment and joy. If this conjecture is valid, we would find that

H3: The effects of religious affiliation on quality of life, sleep quality, depressive moods, anxiety, and stress measured at a later time would be mediated by material goals. That is, one of the reasons non-religious individuals are different from Christians on those outcome variables is that the former holds more strongly onto material goals.

\section{Pursuing Two Sets of Life Goals}

Because material pursuit is regarded as unimportant or even unbiblical in many Christian traditions (with the exception of the "wealth-and-health theology"), material goals and Christian goals can be seen as incompatible. This incompatibility is somewhat analogous to that between workers' safety goals and production goals (McLain and Jarrell 2007), and between university faculty members' research goals and teaching goals (Locke et al. 1994).

The simultaneous pursuit of these two apparently incompatible goals may have negative consequences. For example, some researchers on personality integration have advanced the notion that conflicts among values held by a person would constitute psychological distress 
PURPOSE-DRIVEN LIFE

(Emmons 1999; Koestner et al. 1992; Schwartz 1992, 1994). Sheldon and Kasser (1995) pointed out that well-being is maximized when a person's low-level goals are consistent with high-level goals (vertical coherence). Along this line of research, Burroughs and Rindfleisch (2002) found that materialistic values (which often involve individualistic, competitive acts) were associated with conflict and stress in individuals who also held high collective-oriented values. They also found that value conflict mediated the association between materialistic values and subjective well-being in individuals with high collective-oriented values but not in those with low collective-oriented values. Bouckenooghe, Fontaine, and Vanderheyden (2005) found that working adults with higher value conflicts experienced more stress than others. Owing to resource constraint, attainment of one goal implies non-attainment of another goal to which the individual has an equally strong aspiration. In a review, Riediger (2007) concluded that such interference among goals was negatively associated with subjective well-being. There were, however, no studies on intra-individual goal conflicts involving religious goals.

A second possibility was that the effects of one set of goals dominated over those of the other set. For instance, people holding both material goals and Christian goals might experience poor quality of life and psychological health because of the material goals and in spite of the Christian goals, or experience good outcomes because of the Christian goals and in spite of the material goals. One type of goals merely "overshadowed" the other.

It was also possible that the effects of the Christian goals and material goals on quality of life and psychological outcomes could be independent of each other, with each set of goals exerting its own kind of influence. In view of the mixed and inconclusive evidence in the literature, we would explore how theoretically incompatible goals would interact in affecting 
PURPOSE-DRIVEN LIFE

psychological outcomes, and to determine if the beneficial effects of Christian goals would be attenuated or even reversed in individuals who also pursued material goals.

\section{Method}

\section{Procedures and Participants}

The dataset for this study was drawn from a longitudinal, online panel of surveys on the formation and transformation of beliefs in Chinese people. All survey questions were presented in Chinese. Because religious attitudes and behaviors were one of the themes of this project, Christians were intentionally over-sampled. Details of the overall recruitment and survey procedures were described in [Citations temporarily masked for the purpose of blind review]. Data for this current study were collected in two waves during the fall of 2009 and the spring of 2010, respectively. Life goals and demographic (i.e., age, gender, family income as a proxy of socio-economic status) questions were administered at Wave 1, and all outcome measures at Wave 2. As some life goals (e.g., to complete university education) are intertwined with people's current life stage, for a clearer picture, we included in this study only people who were not fulltime students. All cases were without missing data on the demographic and life goals measures. There were a total of 700 cases, of whom 451 (64\%) were female. The age range was 16 to 67 , with a mean of 32.7 and a SD of 9.3. Six hundred and ninety-four (99\%) respondents reported living in Hong Kong and six (1\%) in Macau. There were 477 who identified themselves as Christians and 223 who reported not having any religious affiliation. To avoid confounding the results, for the present study, we excluded people of other religions, the number of which was small in the dataset anyway.

\section{Predictor Measure - Life Goals}




\section{PURPOSE-DRIVEN LIFE}

Several counselors created a preliminary list of goals that people might want to achieve in a few years' time. They also wrote a few items that describe goals consistent with Christian teaching. Although the informants had not been told about the social scientific taxonomies of life goals, the items they generated were sufficiently diverse in contents, including material goals, family formation goals, and service goals. The items were first edited by one coauthor for clarity and uniformity in format, and then edited again by three other coauthors. Participants indicated whether they wanted to attain the goals in the next ten years, on a four-point scale $(1=$ definitely not; 2 = not very probable; $3=$ possibly; $4=$ absolutely). Providing a time frame to the participants sets this measure apart from other generic life goal measures that resemble value measures. Items written with a Christian content were administered only to the Christian subsample.

We examined the psychometric properties of this instrument with an exploratory factor analysis on the bivariate polychoric correlations (Olsson 1979) among the 18 items using another Christian sample $(\mathrm{N}=988)$ extracted from the larger longitudinal project. On the basis of parallel analysis (Crawford et al. 2010; Horn 1965; Zwick and Velicer 1986), we subjected six factors for Geomin (Browne 2001; Yates 1987) oblique rotation, to identify a simple factor structure with minimal cross-loadings. The resulting model had a reasonable fit (RMSEA $=.069,90 \% \mathrm{CI}$ $=.062-.076$ ). For the purpose of the present study, two sets (i.e., material goals and Christian goals) of items were used. The material goals were: "owning a car or real estate", "securing job promotion and having career achievements that others affirm", "having a high quality material life", and "enjoying a variety of leisure activities, and having fun with friends and peers". The Christian goals were: "proclaiming the Christian faith", "deepening one's spiritual life", 
PURPOSE-DRIVEN LIFE

"pursuing theological studies", and "being actively involved in church ministries". Cronbach's alphas for the material goals and Christian goals were .73 and .83 , respectively.

How these two measures were associated with Schwartz's $(1992,1994)$ ten personal values would provide some evidence of discriminant and convergent validity. Within our sample of 477 individuals, the material goals measure correlated negatively ( $\mathrm{rs}=-.15$ to -.28 ) with the values of conformity, tradition, benevolence, security, and universalism, and positively ( $\mathrm{rs}=.13$ to .29) with the values of stimulation, self-direction, hedonism, achievement, and power. The Christian goals measure correlated negatively ( $\mathrm{rs}=-.23$ to -.33 ) with the values of self-direction, hedonism, and power. It correlated positively ( $r s=.18$ to .34$)$ with the values of conformity, tradition, universalism, and benevolence.

\section{Outcome Measures}

Quality of life (QOL). According to the WHOQOL SRPB Group (2006), it is how well people are able to perform daily activities and how they feel about their lives in physical, social, and psychological functioning. In the present study, it was measured with the 28 -item Hong Kong Chinese version of World Health Organization Quality of Life Measures (WHOQOLBREF(HK); K. F. Leung et al. 1997). Participants responded to each item on a five-point scale. This cross-culturally validated instrument has been widely used in studies of Chinese in Hong Kong (K. F. Leung et al. 2005; Y. S. C. Leung and Tsang 2003; Tsang and Wong 2005). For the present study, we selected 26 items suitable for the population we were studying. Six indices could be derived on the respondents' subjective appraisal of their Physical Health, Psychological Health, Social Relationships, Environment, Overall Quality of Life, and Overall Health. The first four are multi-item measures with Cronbach's alphas between .71 and .86. This measure of QOL was taken in Wave 2, i.e., about six months after we measured life goals. 


\section{PURPOSE-DRIVEN LIFE}

Sleep quality. This refers to the subjective experience of sleep, such as satisfaction with sleep and the feeling of being rested when waking up. Sleep quality plays a role in essentially all body and mind systems affecting both physical and psychological health (Haack and Mullington 2005). Its relationship with life goals has not been studied before. In the present study, sleep quality in the previous month was assessed with the Chinese version of the Pittsburg Sleep Quality Index (PSQI; Buysse et al. 1989; Tsai et al. 2005). The 19-item self-report PSQI yields seven indices, namely subjective sleep quality, sleep latency, sleep duration, habitual sleep efficiency, sleep disturbances, use of sleep medication and daytime dysfunction. The total score (with a range between 0 and 21) represents participants' overall sleep quality, with lower score representing better sleep quality. The Chinese PSQI has acceptable psychometric properties (Tsai et al. 2005), and has been used in Hong Kong (e.g., Tsui and Wing 2009). For our sample, Cronbach's alpha was .60.

Mood. It is the temporary emotional states of mind (namely depression, anxiety, and stress), which sustainably and pervasively influence one's perception of self, others, and the world (American Psychiatric Association 1994). The Chinese version of the 21-item Depression Anxiety Stress Scale (DASS-21) measures participants' mental health in the previous week (Lovibond and Lovibond 1995; Taouk et al. 2001). The Chinese version of DASS-21 has sound psychometric properties (Taouk et al. 2001), and has been widely used in Hong Kong (e.g., Wong et al. 2006). Cronbach's alphas of the three subscales for our sample were .87, .74, and .83, respectively.

\section{Results}

Table 1 presents the demographic profiles of the non-religious and the Christian subsamples, as well as their means and standard deviations on the various life goals and outcome 
PURPOSE-DRIVEN LIFE

variables. Compared with the Christian sub-sample, the non-religious sub-sample was younger, lower in family income, and made up of fewer women. While these differences were controlled for in our data analyses of the full sample, they should be taken into account when interpreting the findings of the two subsamples. The non-religious sub-sample was also predictably higher on material goals, in comparison to the Christians. Consistent with past research, the non-religious sub-sample reported lower QOL and higher depressive symptoms. There were, however, no differences in sleep quality, anxiety, and stress between the two subsamples.

(Insert Tables 1 and 2 here)

\section{Correlational Analyses}

Table 2 shows the correlations among age, life goals, and outcome variables. For the Christian sub-sample, there was a negative correlation between Christian goals and material goals, a phenomenon expected from the religious teaching that one cannot "serve God and mammon" at the same time. Consistent with the observation that people's developmental tasks differ from one life stage to another, age was negatively related to material goals in both subsamples, and positively to Christian goals for the Christian sub-sample. As in previous studies, all six WHOQOL indices were positively correlated with each other, and so were the three mood indices (depression, anxiety, and stress). These two clusters of indices were negatively correlated with each other for both sub-samples, demonstrating good construct validity. Adding strength to the nomological network was the negative association of poor quality of sleep (PSQI) with QOL and positive association with the three mood symptoms scales in both sub-samples.

Material goals and WHOQOL indices were negatively correlated $(r=-.10$ to -.17 for the non-religious sub-sample, and $r=-.09$ to -.21 for the Christian sub-sample). Positive correlations between material goals and mood symptoms were found in the Christian sub-sample $(r=.15$ 
PURPOSE-DRIVEN LIFE

to .21). Similar trends were identified in the non-religious sub-sample, although the effects did not reach statistical significance, except for stress $(r=.14)$.

\section{Regression Analyses}

Supported by the above correlations among religious affiliation, material goals, and the hypothesized outcome variables, we conducted several sets of multiple regression analyses. To minimize the possible impacts from outliers and influential observations, robust regression was used to estimate the regression coefficients (Rousseeuw and Leroy 1987). The bias-corrected and accelerated (BCa) confidence intervals (Efron 1987) for the regression coefficients were constructed based on 2,000 bootstrap samples (Efron 1979; Efron and Tibshirani 1986).

(Insert Table 3 here)

The first set of regression analyses was conducted on all ten outcome variables, with the purpose of elucidating the effects of all predictors in this study. As shown in Table 3, which presents the unstandardized regression coefficients, WHOQOL was unrelated to age, except for QOL-Social Relationship. All six QOL indices could be predicted somewhat by income.

Moreover, women reported higher QOL than men on Social Relationships and QOL-Overall, but poorer on sleep quality. As there were associations between demographic variables and our study variables, we included these demographic variables as controls in all regression analyses.

Religious affiliation predicted QOL-Environmental and QOL-Overall.

The pursuit of material goals predicted low QOL-Physical, low QOL-Psychological, low QOL-Social Relationship, low QOL-Environmental, low QOL-Overall, and low Overall Health, poor sleep quality, depressive moods, anxiety, and stress. In our test of H1, we also examined the interaction effects between religious affiliation and material goals in a moderation model. The 
PURPOSE-DRIVEN LIFE

interaction term was not significant for any outcome variables, indicating that the harmful effects of material goals were generalizable across the religion divide.

We further conducted a separate set of regression analyses on the Christian sub-sample. As shown in Table 4, material goals negatively predicted QOL-Physical, QOL-Psychological, QOL-Environmental, and QOL-Overall. Material goals also positively predicted depression and anxiety. As stated in H2, Christian goals predicted QOL-Physical, QOL-Psychological, QOLSocial, QOL-Overall, and Health Overall. Christian goals also negatively predicted depression and anxiety.

(Insert Table 4 here)

As there was an effect of religious affiliation on QOL-Environmental and QOL-Overall, we proceeded to mediation analyses to test $\mathrm{H} 3$. In each mediation analysis, we fitted two regression models, one predicting the outcome variables with the demographics, religious affiliation and material goals, the other predicting material goals with the demographics and religious affiliation. The first model provided us with information about the direct effect through the regression coefficient of religious affiliation. The coefficient for the indirect effect was calculated by multiplying the coefficient of material goals from the first model and the coefficient of religious affiliation from the second model together. Results showed that for QOLEnvironmental, there was a direct effect $(\mathrm{b}=-.28, \mathrm{SE}=.09,95 \% \mathrm{CI}=-.50$ to -.12$)$ as well as an indirect effect $(b=-.07, \mathrm{SE}=.03,95 \% \mathrm{CI}=-.13$ to -.02$)$. Similar results were obtained for QOLOverall. There was both a direct effect $(\mathrm{b}=-.28, \mathrm{SE}=.14,95 \% \mathrm{CI}=-.21$ to -.05$)$ and an indirect effect $(b=-.12, \mathrm{SE}=.04,95 \% \mathrm{CI}=-.21$ to -.05$)$. Material goals partially mediated the effect of religious affiliation on the two indicators of well-being, providing some support for H3. 
PURPOSE-DRIVEN LIFE

Lastly, to explore if the two sets of life goals would be in conflict with each other for the Christian subsample, we added an interaction term (between Christian goals and materials goals) to the regression models depicted in Table 4. The interaction effect was statistically significant for QOL-Overall $(\mathrm{b}=-.61, \mathrm{SE}=.33,95 \% \mathrm{CI}=-1.15$ to .17$)$ and depression $(\mathrm{b}=.98, \mathrm{SE}=.44$, $95 \% \mathrm{CI}=.21$ to 1.96$)$, but not for other outcome variables. To interpret the two interaction effects, we considered two levels of material goals by taking the standard deviation from its own mean and forming high and low levels of material goals. As can be seen in Figure 1, the positive effects of Christian goals on QOL-Overall were attenuated for the Christians who at the same time pursued material goals. A similar effect was observed for depressive mood. Although those Christians who pursued Christian goals were generally less likely to report depression than those who did not, this advantage diminished for those who at the same time pursued material goals. As for the other outcome variables, the two goals had independent effects.

\section{Discussion}

The primary purpose of this study was to examine how life goals might affect QOL, sleep quality, and mood. Compared to values, life goals constitute a more neutral and objective representation of a person's pursuits. We validated and extended previous cross-sectional findings with data collected about six months apart, from both non-religious and Christian Chinese, outside of a college setting. This allows our findings to be generalized to a broader population.

In support of $\mathrm{H} 1$, we found that material goals predicted depressive and anxiety symptoms, as well as poor QOL. The absence of any moderating effect of religious affiliation on the association between material goals and well-being contradicts the notion that the link between life goals/values and well-being is context-dependent. This context-dependency has 
PURPOSE-DRIVEN LIFE

been reported by, for example, La Barbera and Gürhan (1997), who found that the negative correlation of materialism and well-being only existed in born-again Christians and not in nonborn-again Christians. Another finding supporting the context-dependent view was reported by Li and Bond (2010). They noted a positive correlation between secularist values and life satisfaction in highly-developed nations. In the same vein, Ingrid, Majda, and Dubravka (2009) proposed that extrinsic, financial aspirations are not necessarily detrimental to well-being in collectivist countries.

In contrast to these context-dependence findings, our observation that materialism strivings are negatively correlated with quality of life and psychological outcomes, even in a highly materialistic and secular society that exalts power and wealth over many virtues, regardless of the person's financial status, is supportive of the SDT (Emmons 2003; Martos and Kopp 2012). It also echoes Kasser and Ahuvia's (2002) findings that despite being in an environment where materialism is cherished, business students with strong material aspirations reported low levels of self-actualization, vitality, and happiness, as well as higher levels of anxiety and physical symptoms.

Also of interest was the novel finding that among Christian believers, goals that target deepening and practice of their religious faith were conducive to a wide range of positive psychological health outcomes. As postulated in $\mathrm{H} 2$, the beneficial effects of Christian goals were particularly robust and widespread, with significant findings on five of the six WHOQOL indices, as well as two mood indicators. Some may speculate that the health advantage of religious or similar metaphysical goals may be confined to those who already have their other more basic needs satisfied. As for people who are still struggling to make ends meet, the argument goes, the pursuit of religious goals at the expense of the pursuit of material goals 


\section{PURPOSE-DRIVEN LIFE}

would not have much benefit. However, a follow-up moderation analysis of our data showed that the interaction term between Christian goals and family income was not a statistically significant predictor of any of the outcome variables except for QOL-Psychological $(b=-.31, \mathrm{SE}=.12$, $95 \% \mathrm{CI}=-.48$ to -.02$)$ and anxiety $(\mathrm{b}=.25, \mathrm{SE}=.13,95 \% \mathrm{CI}=-.02$ to .46$)$. In fact, the additional analyses revealed that the positive effects of Christian goals were stronger among those with lower income than those with higher income.

From a cognitive perspective, individuals who consider the pursuits of religious goals a high priority may be more ready to engage in meaning making (Park 2010) when confronted with ups and downs in life. They would adopt alternative perspectives in face of changes and adversities. As a result they are less vulnerable to negative mood and poor QOL, even when not all aspects of life are abundant. Another possible explanation for the link between better psychological outcomes and Christian goals is that the pursuit of such goals is congruent with the social atmosphere of the religious community to which one belongs. This study does not provide direct evidence pertaining to this second explanation. Nevertheless, the fact that the patterns of life goal effects in our two sub-samples are quite similar, and that religious affiliation does not moderate the adverse effects of material goals suggest that the effects of life goals on the measured outcomes are rather direct and intrinsic, and not contingent upon the social environment of religious institutions. Taken together, our findings corroborate with the contention that although material wealth (family income in this study) may contribute to better subjective well-being, striving for material goals may bring about lower life contentment, disrupted sleep, and emotional disturbances.

Another novel finding from the present study pertains to the mediational role of life goals in the link between religious affiliation and well-being. Consistent with past research results, 


\section{PURPOSE-DRIVEN LIFE}

Christians and non-believers were different in their reported quality of life. Further analyses showed that the two significant effects (on QOL-Environmental and QOL-Overall) could be explained partially in terms of the non-believers holding more strongly than the Christians do onto material goals. Even for the other four QOL indices where statistical significance of the original religious affiliation effect was not reached, mediational analyses still revealed an indirect effect of religious affiliation through material goals on the outcome variables. On a related note, in addition to religious affiliation, age was also a significant correlate of material goals. A lot has been written in recent years about materialism among young people (e.g., Goldberg et al. 2003). This goal orientation gradually develops during peoples' first 15 years of life. Early adolescence is the time when materialism peaks (Chaplin and John 2007). However, as people mature, they realize that material goods are not the only things that one needs in life and should be striving for.

Regarding a possible intrapersonal conflict between material goals and Christian goals, our findings call for a more complex interpretation. On anxiety as well as five of the six WHOQOL indices, the effects of pursuing Christian goals and foregoing material goals appear to be independent and additive. In other words, the pursuit of Christian goals seems to protect health and sleep and would cancel out the potentially deleterious effects of material goals. However, on QOL-Overall and depressive symptoms, there was an interaction effect between Christian goals and material goals. This implies that the pursuit of Christian goals have a positive psychological effect only for those people without an equally strong striving for material goals. That is, those believers who hold onto both sets of goals at the same time are no better in terms of overall quality of life and mood than those who emphasize material goals and not Christian 


\section{PURPOSE-DRIVEN LIFE}

goals at all. Further research is needed on the mental health implications of compatibility/incompatibility between people's spiritual goals and secular goals.

Researching Christian goals (instead of religious constructs such as church attendance and frequency of prayer) can supplement the existing literature on religiosity. The benefit is that this aspect of religiosity can be investigated along with other non-religious goals. This allows for comparisons of the impact of different types of goals at the same conceptual level. Furthermore, if this approach is shown to be fruitful, future researchers can apply similar methodologies to understand the effects of different religions, as well as to make fine distinctions among people of the same religion.

The present study is limited in certain aspects, which should be addressed in future research. First, the experiences that pursuing a life goal engenders may be quite different from the experiences of attaining the life goal. Therefore, it would be fruitful to examine consequences of the attainment and non-attainment of different life goals (see, e.g., Headey 2008). Second, we have compared non-believers with Christians only, and measured life goals that are based on the Christian faith. Generalizability of our present findings could be evaluated by examining the effects of goals based on religions other than Christianity. Third, we should not ignore the possibility of well-being influencing people's construction of life goals. For example, SalmelaAro and Nurmi's (1997) data suggest that there may be an accumulative process by which high self-esteem strengthens subsequent family-related goals, which might then further lead to higher self-esteem. Our present approach of regressing outcome measures collected at Wave 2 on life goal measures at Wave 1 does not allow us to confidently rule out this possibility. Future research should therefore use a cross-lagged design for a more definitive elucidation of the causality between life goals and well-being. 


\section{PURPOSE-DRIVEN LIFE}

Notwithstanding the need for more research, we have successfully demonstrated that life goals can be a new explanation for the widely reported religion-well-being link (e.g., Smith et al. 2003; Witter et al. 1985). That is, in addition to explanations such as the availability of social support network to religious people, social involvement, perceived control, and religious coping, life goals may be another mechanism through which religiosity leads to well-being (see, e.g., McCullough and Willoughby 2009). Our findings show that not only can some life goals explain why people with religious faiths have better psychological outcomes, they can also explain why only some but not all religious persons feel good and are content with their lives. 
PURPOSE-DRIVEN LIFE

\section{References}

American Psychiatric Association (1994). Diagnostic and statistical manual of mental disorders. Washington, DC: American Psychiatric Association.

Ano, G. G., \& Vasconcelles, E. B. (2005). Religious coping and psychological adjustment to stress: A meta-analysis. Journal of Clinical Psychology, 61(4), 461-480, doi:10.1002/jclp.20049.

Bennett, K. S., \& Shepherd, J. M. (2013). Depression in Australian women: The varied roles of spirituality and social support. Journal of Health Psychology, 18(3), 429-438, doi: $10.1177 / 1359105312443400$.

Bouckenooghe, D., Fontaine, J., \& Vanderheyden, K. (2005). The prediction of stress by values and value conflict. Journal of Psychology, 139(4), 369-382, doi:10.3200/JRLP.139.4.369-384.

Browne, M. W. (2001). An overview of analytic rotation in exploratory factor analysis. Multivariate Behavioral Research, 36(1), 111-150, doi:10.1207/s15327906mbr3601_05.

Brunstein, J. C. (1993). Personal goals and subjective well-being: A longitudinal study. Journal of Personality and Social Psychology, 65(5), 1061-1070, doi:10.1037/00223514.65.5.1061.

Burroughs, J. E., \& Rindfleisch, A. (2002). Materialism and well-being: A conflicting values perspective. Journal of Consumer Research, 29(3), 348-370, doi:10.1086/344429.

Buysse, D. J., Reynolds, C. F., III, Monk, T. H., Berman, S. R., \& Kupfer, D. J. (1989). The Pittsburgh sleep quality index: A new instrument for psychiatric practice and research. Psychiatry Research, 28(2), 193-213, doi:10.1016/0165-1781(89)90047-4.

Calvin, J. (1536/1995). Institutes of the Christian religion. Grand Rapids, MI: Eerdmans. 


\section{PURPOSE-DRIVEN LIFE}

Chaplin, L. N., \& John, D. R. (2007). Growing up in a material world: Age differences in materialism in children and adolescents. Journal of Consumer Research, 34(4), 480-493, doi:10.1086/518546.

Chida, Y., Steptoe, A., \& Powell, L. H. (2009). Religiosity/spirituality and mortality. Psychotherapy and Psychosomatics, 78(2), 81-90, doi:10.1159/000190791.

Christopher, A. N., Saliba, L., \& Deadmarsh, E. J. (2009). Materialism and well-being: The mediating effect of locus of control. Personality and Individual Differences, 46(7), 682686, doi:10.1016/j.paid.2009.01.003.

Conrad, N., Doering, B. K., Rief, W., \& Exner, C. (2010). Looking beyond the importance of life goals. The personal goal model of subjective well-being in neuropsychological rehabilitation. Clinical Rehabilitation, 24(5), 431-443, doi:10.1177/0269215509358930.

Crawford, A. V., Green, S. B., Levy, R., Lo, W.-J., Scott, L., Svetina, D., et al. (2010). Evaluation of parallel analysis methods for determining the number of factors. Educational and Psychological Measurement, 70(6), 885-901, doi:10.1177/0013164410379332.

Deci, E. L., \& Ryan, R. M. (2000). The 'What' and 'Why' of Goal Pursuits: Human Needs and the Self-Determination of Behavior. [research-article]. Psychological Inquiry, 11(4), 227-268, doi:10.2307/1449618.

Efron, B. (1979). Bootstrap methods: Another look at the jackknife. [research-article]. The Annals of Statistics, 7(1), 1-26, doi:10.1214/aos/1176344552.

Efron, B. (1987). Better bootstrap confidence intervals: Rejoinder. Journal of the American Statistical Association, 82(397), 198-200, doi:10.2307/2289153. 


\section{PURPOSE-DRIVEN LIFE}

Efron, B., \& Tibshirani, R. (1986). Bootstrap methods for standard errors, confidence intervals, and other measures of statistical accuracy. Statistical Science, 1(1), 54-75, doi:10.1214/ss/1177013815.

Ellison, C. G. (1991). Religious involvement and subjective well-being. Journal of Health and Social Behavior, 32(1), 80-99, doi:10.2307/2136801.

Ellison, C. G. (1993). Religious involvement and self perception among Black Americans. Social Forces, 71(4), 1027-1055, doi:10.2307/2580129.

Emmons, R. A. (1986). Personal strivings: An approach to personality and subjective well-being. Journal of Personality and Social Psychology, 51(5), 1058-1068, doi:10.1037/00223514.51.5.1058.

Emmons, R. A. (1999). Religion in the psychology of personality: An introduction. Journal of Personality, 67(6), 873-888, doi:10.1111/1467-6494.00076.

Emmons, R. A. (2003). Personal goals, life meaning, and virtue: Wellsprings of a positive life. In C. L. M. Keyes, J. Haidt, \& M. E. P. Seligman (Eds.), Flourishing: Positive psychology and the life well-lived (pp. 105-128). Washington, DC: American Psychological Association.

Emmons, R. A. (2005). Striving for the sacred: Personal goals, life meaning, and religion. Journal of Social Issues, 61(4), 731-745, doi:10.1111/j.1540-4560.2005.00429.x.

Gabrielsen, L. E., Ulleberg, P., \& Watten, R. G. (2012). The Adolescent Life Goal Profile Scale: Development of a new scale for measurements of life goals among young people. Journal of Happiness Studies, 13(6), 1053-1072, doi:10.1007/s10902-011-9306-2. 


\section{PURPOSE-DRIVEN LIFE}

Goldberg, M. E., Gorn, G. J., Peracchio, L. A., \& Bamossy, G. (2003). Understanding materialism among youth. Journal of Consumer Psychology, 13(3), 278-288, doi:10.1207/S15327663JCP1303_09.

Green, M., \& Elliott, M. (2010). Religion, health, and psychological well-being. Journal of Religion and Health, 49(2), 149-163, doi:10.1007/s10943-009-9242-1.

Haack, M., \& Mullington, J. M. (2005). Sustained sleep restriction reduces emotional and physical well-being. Pain, 119(1-3), 56-64, doi:10.1016/j.pain.2005.09.011.

Headey, B. (2008). Life goals matter to happiness: A revision of set-point theory. Social Indicators Research, 86(2), 213-231, doi:10.1007/s11205-007-9138-y.

Headey, B., Schupp, J., Tucci, I., \& Wagner, G. G. (2010). Authentic happiness theory supported by impact of religion on life satisfaction: A longitudinal analysis with data for Germany. The Journal of Positive Psychology, 5(1), 73-82, doi:10.1080/17439760903435232.

Horn, J. L. (1965). A rationale and test for the number of factors in factor analysis. Psychometrika, 30(2), 179-185, doi:10.1007/bf02289447.

Ingrid, B., Majda, R., \& Dubravka, M. (2009). Life goals and well-being: Are extrinsic aspirations always detrimental to well-being? Psychological Topics, 18(2), 317-334.

Jackson, B. R., \& Bergeman, C. S. (2011). How does religiosity enhance well-being? The role of perceived control. Psychology of Religion and Spirituality, 3(2), 149-161, doi:10.1037/a0021597.

Kasser, T., \& Ahuvia, A. (2002). Materialistic values and well-being in business students. European Journal of Social Psychology, 32(1), 137-146, doi:10.1002/ejsp.85. 


\section{PURPOSE-DRIVEN LIFE}

Kasser, T., \& Ryan, R. M. (1996). Further examining the American dream: Differential correlates of intrinsic and extrinsic goals. Personality and Social Psychology Bulletin, 22(3), 280-287, doi:10.1177/0146167296223006.

Keng, K. A., Jung, K., Jiuan, T. S., \& Wirtz, J. (2000). The influence of materialistic inclination on values, life satisfaction and aspirations: An empirical analysis. Social Indicators Research, 49(3), 317-333, doi:10.1023/A:1006956602509.

King, L. A. (2001). The health benefits of writing about life goals. Personality and Social Psychology Bulletin, 27(7), 798-807, doi:10.1177/0146167201277003.

Klug, H. J. P., \& Maier, G. W. (2014). Linking goal progress and subjective well-being: A metaanalysis. Journal of Happiness Studies, doi:10.1007/s10902-013-9493-0.

Koenig, H. G., Cohen, H. J., Blazer, D. G., \& Kudler, H. S. (1995). Religious coping and cognitive symptoms of depression in elderly medical patients. Psychosomatics: Journal of Consultation Liaison Psychiatry, 36(4), 369-375, doi:10.1016/S0033-3182(95)71646-2.

Koenig, H. G., Gittelman, D., Branski, S., Brown, S., Stone, P., \& Ostrow, B. (1998). Depressive symptoms in elderly medical-surgical patients hospitalized in community settings. The American Journal of Geriatric Psychiatry, 6(1), 14-23, doi:10.1097/00019442199800610-00003.

Koestner, R., Bernieri, F., \& Zuckerman, M. (1992). Self-regulation and consistency between attitudes, traits, and behaviors. Personality and Social Psychology Bulletin, 18(1), 52-59, doi:10.1177/0146167292181008.

Krause, N. (1995). Religiosity and self-esteem among older adults. The Journals of Gerontology: Series B, 50B(5), P236-P246, doi:10.1093/geronb/50B.5.P236. 


\section{PURPOSE-DRIVEN LIFE}

La Barbera, P. A., \& Gürhan, Z. (1997). The role of materialism, religiosity, and demographics in subjective well-being. Psychology \& Marketing, 14(1), 71-97, doi:10.1002/(sici)15206793(199701)14:1<71::aid-mar5>3.0.co;2-1.

Lawler-Row, K. A. (2010). Forgiveness as a mediator of the religiosity—health relationship. Psychology of Religion and Spirituality, 2(1), 1-16, doi:10.1037/a0017584.

Leak, G. K., DeNeve, K. M., \& Greleman, A. J. (2007). The relationship between spirituality, assessed through self-transcendent goal strivings, and positive psychological attributes. Research in the Social Scientific Study of Religion, 18, 263-280, doi:10.1163/ej.9789004158511.i-301.102.

Lekes, N., Hope, N. H., Gouveia, L., Koestner, R., \& Philippe, F. L. (2012). Influencing value priorities and increasing well-being: The effects of reflecting on intrinsic values. The Journal of Positive Psychology, 7(3), 249-261, doi:10.1080/17439760.2012.677468.

Leung, K. F., Tay, M., Cheng, S., \& Lin, F. (1997). Hong Kong Chinese version World Health Organisation Quality of Life - Abbreviated version. Hong Kong: Hong Kong Hospital Authority.

Leung, K. F., Wong, W. W., Tay, M. S. M., Chu, M. M. L., \& Ng, S. S. W. (2005). Development and validation of the interview version of the Hong Kong Chinese WHOQOL-BREF. Quality of Life Research: An International Journal of Quality of Life Aspects of Treatment, Care \& Rehabilitation, 14(5), 1413-1419, doi:10.1007/s11136-004-4772-1.

Leung, Y. S. C., \& Tsang, C. W. P. L. (2003). Quality of life of parents who have children with disabilities. Hong Kong Journal of Occupational Therapy, 13(1), 19-24, doi:10.1016/s1569-1861(09)70019-1. 


\section{PURPOSE-DRIVEN LIFE}

Li, L. M. W., \& Bond, M. H. (2010). Does individual secularism promote life satisfaction? The moderating role of societal development. Social Indicators Research, 99(3), 443-453, doi:10.2307/40927605.

Locke, E. A., Smith, K. G., Erez, M., Chah, D.-O., \& Schaffer, A. (1994). The effects of intraindividual goal conflict on performance. Journal of Management, 20(1), 67-91, doi:10.1177/014920639402000104.

Lovibond, S. H., \& Lovibond, P. F. (1995). Manual for the Depression Anxiety Stress Scales (2nd ed.). Sydney: Psychology Foundation.

Martos, T., \& Kopp, M. S. (2012). Life goals and well-being: Does financial status matter? Evidence from a representative Hungarian sample. Social Indicators Research, 105(3), 561-568, doi:10.1007/s11205-011-9788-7.

McCullough, M. E., Hoyt, W. T., Larson, D. B., Koenig, H. G., \& Thoresen, C. (2000).

Religious involvement and mortality: A meta-analytic review. Health Psychology, 19(3), 211-222, doi:10.1037/0278-6133.19.3.211.

McCullough, M. E., \& Willoughby, B. L. B. (2009). Religion, self-regulation, and self-control: Associations, explanations, and implications. Psychological Bulletin, 135(1), 69-93, doi:10.1037/a0014213.

McLain, D. L., \& Jarrell, K. A. (2007). The perceived compatibility of safety and production expectations in hazardous occupations. Journal of Safety Research, 38(3), 299-309, doi:10.1016/j.jsr.2006.10.011.

McNamara, P., Durso, R., \& Harris, E. (2006). Life goals of patients with Parkinson's disease: a pilot study on correlations with mood and cognitive functions. Clinical Rehabilitation, 20(9), 818-826, doi:10.1177/0269215506070811 


\section{PURPOSE-DRIVEN LIFE}

Nicholson, A., Rose, R., \& Bobak, M. (2009). Association between attendance at religious services and self-reported health in 22 European countries. Social Science \& Medicine, 69(4), 519-528, doi:10.1016/j.socscimed.2009.06.024.

Niemiec, C. P., Ryan, R. M., Deci, E. L., \& Williams, G. C. (2009). Aspiring to physical health: The role of aspirations for physical health in facilitating long-term tobacco abstinence. Patient Education and Counseling, 74(2), 250-257, doi:10.1016/j.pec.2008.08.015.

Norris, J. I., \& Larsen, J. T. (2011). Wanting more than you have and it's consequences for wellbeing. Journal of Happiness Studies, 12(5), 877-885, doi:10.1007/s10902-010-9232-8.

Olsson, U. (1979). Maximum likelihood estimation of the polychoric correlation coefficient. Psychometrika, 44(4), 443-460, doi:10.1007/bf02296207.

Park, C. L. (2010). Making sense of the meaning literature: An integrative review of meaning making and its effects on adjustment to stressful life events. Psychological Bulletin, 136(2), 257-301, doi:10.1037/a0018301.

Plante, T. G., \& Sherman, A. C. (Eds.). (2001). Faith and health: Psychological perspectives. New York, NY: Guilford Press.

Richards, J. M., Jr. (1966). Life goals of American college freshmen. Journal of Counseling Psychology, 13(1), 12-20, doi:10.1037/h0023049.

Riediger, M. (2007). Interference and facilitation among personal goals: Age-group differences and associations with well-being and behavior. In B. R. Little, K. Salmela-Aro, \& S. D. Phillips (Eds.), Personal project pursuit: Goals, action, and human flourishing (pp. 119143). Mahwah, NJ: Lawrence Erlbaum Associates. 


\section{PURPOSE-DRIVEN LIFE}

Roberts, J. A., \& Clement, A. (2007). Materialism and satisfaction with over-all quality of life and eight life domains. Social Indicators Research, 82(1), 79-92, doi:10.1007/s11205006-9015-0.

Rousseeuw, P. J., \& Leroy, A. M. (1987). Robust regression and outlier detection. New York, NY: Wiley.

Salmela-Aro, K., \& Nurmi, J.-E. (1997). Goal contents, well-being, and life context during transition to university: A longitudinal study. International Journal of Behavioral Development, 20(3), 471-491, doi:10.1080/016502597385234.

Saroglou, V., Delpierre, V., \& Dernelle, R. (2004). Values and religiosity: A meta-analysis of studies using Schwartz's model. Personality and Individual Differences, 37(4), 721-734, doi:10.1016/j.paid.2003.10.005.

Schnitker, S. A., Felke, T. J., Barrett, J. L., \& Emmons, R. A. (2014). Longitudinal study of religious and spiritual transformation in adolescents attending young life summer camp: Assessing the epistemic, intrapsychic, and moral sociability functions of conversion. Psychology of Religion and Spirituality, 6(2), 83-93, doi:10.1037/a0035359.

Schwartz, S. H. (1992). Universals in the content and structure of values: Theoretical advances and empirical tests in 20 countries. In M. P. Zanna (Ed.), Advances in experimental social psychology, Vol. 25. (pp. 1-65). San Diego, CA US: Academic Press.

Schwartz, S. H. (1994). Are there universal aspects in the structure and contents of human values? part of a symposium on: Human values and social issues, 50(4), 19-45, doi:10.1111/j.1540-4560.1994.tb01196.x. 


\section{PURPOSE-DRIVEN LIFE}

Sheldon, K. M., \& Kasser, T. (1995). Coherence and congruence: Two aspects of personality integration. Journal of Personality and Social Psychology, 68(3), 531-543, doi:10.1037/0022-3514.68.3.531.

Sheldon, K. M., Ryan, R. M., Deci, E. L., \& Kasser, T. (2004). The independent effects of goal contents and motives on well-being: It's both what you pursue and why you pursue it. Personality and Social Psychology Bulletin, 30(4), 475-486, doi: $10.1177 / 0146167203261883$.

Shor, E., \& Roelfs, D. J. (2013). The longevity effects of religious and nonreligious participation: A meta-analysis and meta-regression. Journal for the Scientific Study of Religion, 52(1), 120-145, doi:10.1111/jssr.12006.

Smith, T. B., McCullough, M. E., \& Poll, J. (2003). Religiousness and depression: Evidence for a main effect and the moderating influence of stressful life events. Psychological Bulletin, 129(4), 614-636, doi:10.1037/0033-2909.129.4.614.

Taouk, M., Lovibond, P. F., \& Laube, R. (2001). Psychometric properties of a Chinese version of the short Depression Anxiety Stress Scales (DASS21). Report for New South Wales Transcultural Mental Health Centre. Sydney: Cumberland Hospital.

Teismann, T., Het, S., Grillenberger, M., Willutzki, U., \& Wolf, O. T. (2013). Writing about life goals: Effects on rumination, mood and the cortisol awakening response. Journal of Health Psychology, doi:10.1177/1359105313490774.

Tsai, P.-S., Wang, S.-Y., Wang, M.-Y., Su, C.-T., Yang, T.-T., Huang, C.-J., et al. (2005). Psychometric evaluation of the Chinese version of the Pittsburgh Sleep Quality Index (CPSQI) in primary insomnia and control subjects. Quality of Life Research: An 
PURPOSE-DRIVEN LIFE

International Journal of Quality of Life Aspects of Treatment, Care \& Rehabilitation, 14(8), 1943-1952, doi:10.1007/s11136-005-4346-x.

Tsang, H. W. H., \& Wong, A. (2005). Development and validation of the Chinese version of Indiana Job Satisfaction Scale (CV-IJSS) for people with mental illness. International Journal of Social Psychiatry, 51(2), 177-191, doi:10.1177/0020764005056766.

Tsui, Y. Y., \& Wing, Y. K. (2009). Study on the sleep patterns and problems of university business students in Hong Kong. Journal of American College Health, 58(2), 167-176, doi:10.1080/07448480903221418.

Vansteenkiste, M., Lens, W., \& Deci, E. L. (2006). Intrinsic versus extrinsic goal contents in self-determination theory: Another look at the quality of academic motivation.

Educational Psychologist, 41(1), 19-31, doi:10.1207/s15326985ep4101_4.

Vansteenkiste, M., Neyrinck, B., Niemiec, C. P., Soenens, B., De Witte, H., \& Van Den Broeck, A. (2007). On the relations among work value orientations, psychological need satisfaction and job outcomes: A self-determination theory approach. Journal of Occupational \& Organizational Psychology, 80(2), 251-277, doi:10.1348/096317906X111024.

Vansteenkiste, M., Soenens, B., \& Duriez, B. (2008). Presenting a positive alternative to strivings for material success and the thin-ideal: Understanding the effects of extrinsic relative to intrinsic goal pursuits. In S. J. Lopez (Ed.), Positive psychology: Exploring the best in people (Vol. 4, pp. 57-86). Westport, CT: Greenwood Publishing Company.

WHOQOL SRPB Group (2006). A cross-cultural study of spirituality, religion, and personal beliefs as components of quality of life. Social Science \& Medicine, 62(6), 1486-1497, doi:10.1016/j.socscimed.2005.08.001. 


\section{PURPOSE-DRIVEN LIFE}

Williams, G. C., Cox, E. M., Hedberg, V. A., \& Deci, E. L. (2000). Extrinsic life goals and health-risk behaviors in adolescents. Journal of Applied Social Psychology, 30(8), 17561771, doi:10.1111/j.1559-1816.2000.tb02466.x.

Witter, R. A., Stock, W. A., Okun, M. A., \& Haring, M. J. (1985). Religion and subjective wellbeing in adulthood: A quantitative synthesis. Review of Religious Research, 26(4), 332342, doi:10.2307/3511048.

Wong, J. G. W. S., Cheung, E. P. T., Chan, K. K. C., Ma, K. K. M., \& Tang, S. W. (2006). Webbased survey of depression, anxiety and stress in first-year tertiary education students in Hong Kong. Australian and New Zealand Journal of Psychiatry, 40(9), 777-782, doi:10.1111/j.1440-1614.2006.01883.x.

Yates, A. (1987). Multivariate exploratory data analysis: A perspective on exploratory factor analysis. Albany, NY: State University of New York Press.

Zwick, W. R., \& Velicer, W. F. (1986). Comparison of five rules for determining the number of components to retain. Psychological Bulletin, 99(3), 432-442, doi:10.1037/00332909.99.3.432. 
PURPOSE-DRIVEN LIFE

Table 1.Means, Standard Deviations and Comparative Statistics of the Non-Religious and the Christian Sub-samples

\begin{tabular}{|c|c|c|c|c|}
\hline & $\begin{array}{r}\text { Non-religious } \\
(\mathrm{N}=223)\end{array}$ & $\begin{array}{r}\text { Christian } \\
(\mathrm{N}=477)\end{array}$ & Significance test $\mathrm{t}^{\mathrm{a}}$ & Effect size $^{b}$ \\
\hline Age & $28.20(6.96)$ & $34.74(9.48)$ & $t(573)=-10.26 * * *$ & .79 \\
\hline Gender (\% Female) & $52.91 \%$ & $69.81 \%$ & $\chi^{2}(1)=18.93 * * *$ & .16 \\
\hline Income (in HK\$) & & & $\chi^{2}(5)=11.45 *$ & .13 \\
\hline$<10000$ & $7.62 \%$ & $13.00 \%$ & & \\
\hline $10001-20000$ & $30.04 \%$ & $28.51 \%$ & & \\
\hline 20001-30000 & $21.97 \%$ & $16.14 \%$ & & \\
\hline $30001-40000$ & $16.59 \%$ & $12.58 \%$ & & \\
\hline $40001-50000$ & $10.31 \%$ & $10.69 \%$ & & \\
\hline$\geq 50001$ & $13.45 \%$ & $19.08 \%$ & & \\
\hline Material life goals & $3.22(.53)$ & $2.70(.66)$ & $t(527)=11.18 * * *$ & .87 \\
\hline Christian life goals & -- & $3.17(.60)$ & -- & \\
\hline QOL - Physical health & $14.41(2.24)$ & $14.90(2.01)$ & $t(384)=-2.74 * *$ & .23 \\
\hline QOL - Psychological health & $13.06(2.58)$ & $13.95(2.36)$ & $t(387)=-4.32 * * *$ & .36 \\
\hline QOL - Social relationships & $13.47(3.04)$ & $13.96(2.78)$ & $t(383)=-1.97 *$ & .17 \\
\hline QOL - Environmental & $13.24(2.16)$ & $14.13(2.08)$ & $t(408)=-5.04 * * *$ & .42 \\
\hline QOL - Overall & $3.32(.84)$ & $3.60(.75)$ & $t(383)=-4.23 * * *$ & .36 \\
\hline QOL - Overall Health & $2.93(.86)$ & $3.11(.75)$ & $t(365)=-2.56 *$ & .22 \\
\hline PSQI & $6.29(2.79)$ & $6.29(2.76)$ & $t(338)=0.02$ & .00 \\
\hline Depression & $4.81(4.27)$ & $3.55(3.66)$ & $t(380)=3.78 * * *$ & .32 \\
\hline Anxiety & $3.42(3.18)$ & $3.08(2.72)$ & $t(379)=1.40$ & .12 \\
\hline Stress & $6.03(4.22)$ & $5.72(3.66)$ & $t(383)=0.93$ & .08 \\
\hline
\end{tabular}

Note:

${ }^{a}$ The Welch procedure was used to address the issue of heterogeneity of variance in the $t$-tests.

${ }^{\text {b}}$ Cohen's $d$ and Cramer's $V$ are reported as the corresponding measures of effect size for the Welch test and chi-squared test.

$* p<.05 ; * * p<.01 ; * * * p<.001$ 